\title{
The Effect of Workplace Loneliness on Silence Behavior
}

\section{-The Role of Team-Member Exchange and Psychological Capital}

\author{
Lin Guo \\ Jinan University, Guangzhou, China \\ Email:2668925054@qq.com
}

How to cite this paper: Guo, L. (2020) The Effect of Workplace Loneliness on Silence Behavior-The Role of Team-Member Exchange and Psychological Capital. Psychology, 11, 467-479.

https://doi.org/10.4236/psych.2020.113032

Received: February 21, 2020

Accepted: March 28, 2020

Published: March 31, 2020

Copyright $\odot 2020$ by author(s) and Scientific Research Publishing Inc. This work is licensed under the Creative Commons Attribution International License (CC BY 4.0).

http://creativecommons.org/licenses/by/4.0/

(c) (i) Open Access

\begin{abstract}
The purpose of this study was to explore the comprehensive effects of workplace loneliness, silence behavior, team member exchange and psychological capital. At present, the research on workplace loneliness is still in the preliminary stage. Although some studies have shown that workplace loneliness has a direct impact on job outcomes, the mechanism of the two needs to be further studied. In this study, a phased multi-source questionnaire survey method was adopted. The questionnaires were distributed and collected, including 295 subjects. The results show that 1 ) workplace loneliness has a significant negative impact on team member exchange; 2 ) team member exchange has a significant negative impact on silence behavior; 3 ) team member exchange plays a mediating role between loneliness and silence behavior; 4) psychological capital moderates the direct effect of workplace loneliness on silence behavior; 5) psychological capital moderates the indirect effect of workplace loneliness on silence behavior through team member exchange.
\end{abstract}

\section{Keywords}

Workplace Loneliness, Silence Behavior, Team Member Exchange, Psychological Capital

\section{Introduction}

The social transformation and rapid economic development have brought many problems to the workplace, which will lead to the spread of workplace loneliness to varying degrees. Workplace loneliness, has been a common feeling of the current workplace staff. As a common negative emotion in the workplace, workplace loneliness will bring a series of negative effects on employees and organizations 
(Ozcelik \& Barsade, 2018; Peng, Chen, Xia, \& Ran, 2017; Chen, Wen, Peng, \& Liu, 2016). Despite the unprecedented opportunities and dilemmas that lie ahead of us today, emotional needs, the truest desires of the human heart, have never changed. As a basic human experience, everyone may have experienced loneliness more or less. Especially in this information age, loneliness has become more common due to the increasing psychological distance between people (Wright, 2005).

However, previous studies on loneliness show that environmental factors, especially in the work environment, have been neglected. Some studies have pointed out that the possibility and persistence of loneliness experienced in work is greater than that experienced in personal life (Dussault \& Thibodeau, 1997; Reinking \& Bell, 1991). If employees cannot deal with various complicated interpersonal relationships in the workplace, they are likely to experience loneliness in the workplace. As is known to all, modern offices have office partitions and the popularization of science and technology and the emergence of virtual team make employees basic at work do not need to leave her own office location. Even if need to contact the person sitting beside, can be directly through the network to send information, coupled with the fierce competition in the workplace, making interactions between members of the organization is increasingly difficult to maintain. Workplace loneliness thus problems naturally also increasingly prominent, the study of employee's workplace loneliness is very necessary. Therefore, we will carry out our research on workplace loneliness. Starting from workplace loneliness, we will discuss its impact on the team-member exchange the work environment and its impact on the subsequent employee silence behavior. We think that workplace loneliness has a negative impact on team-member exchange which promotes more silence behaviors among employees. In addition, we think that the psychological capital level of employees themselves may mitigate this negative effect, that is, the higher the psychological capital level is, the fewer negative results will be produced.

\section{Theory and Hypothesis Development}

In this section we will focus on how we build the model. First, we will introduce in detail the main theory used to explain the model, namely social exchange theory, and explain how to use this theory to construct the model, so as to propose a theoretical model based on workplace loneliness. Secondly, we will elaborate on how to explain the relationships in the model using social exchange theory and propose five hypotheses of this study.

\subsection{Social Exchange Theory}

Social exchange theory emerged in the late 1950s as a micro study of human behavior using economic, sociological, and psychological theories (Homans, 1958). Social exchange refers to the reciprocity of interests, which means that one party provides help and support to the other party, so that the other party has the ob- 
ligation to return, but does not know whether or when the other party will return, so this kind of exchange relationship has uncertainties and risks (Blau, 1964). The implicit condition of exchange is that the two sides achieve mutual benefit through the exchange of their own unique resources, the core of which is self-interest and interdependence (Lawler \& Thye, 1999; Cook, Cheshire, Rice, \& Nakagawa, 2013). The establishment of employee-organization relationship means that employees exchange their individual labor for rewards and their loyalty to the organization for their care and support. On the other hand, through the hard work of employees, the organization has greater development; the formation of the interdependent relationship between employees and the organization is the formation of a social exchange relationship (Rhoades \& Eisenberger, 2002). The core of social exchange theory is based on the principle of reciprocity. When one party offers help to the other or gives some resources to the other, the party being helped has the obligation to repay the person who gives help, so as to build a moral norm of social exchange (Gouldner, 1960). We will build our model on the basis of social exchange theory. Loneliness as an employee in the workplace in the workplace, a lonely experience (Wright, 2005; Wright et al., 2006), may represent not experience to help other colleagues in the team or other supportive and positive team resources (e.g., good emotional exchange, and interpersonal and team support, etc.), resulting in a series of negative consequences, such as low quality of the team members. However, this kind of low-quality team-member exchange may further aggravate the loneliness and alienation of employees in the team, resulting in more silence behaviors at work. Therefore, this research will be based on social exchange theory, study the effects of loneliness for team members to exchange in the workplace, as well as team-member exchange in the workplace mediating role between loneliness and silence behavior of employees, at the same time introducing the psychological capital is moderator variable, discusses it as a positive resources supplement, how to weaken the negative consequences of a workplace loneliness. Thus, we construct the following theoretical model (see Figure 1).

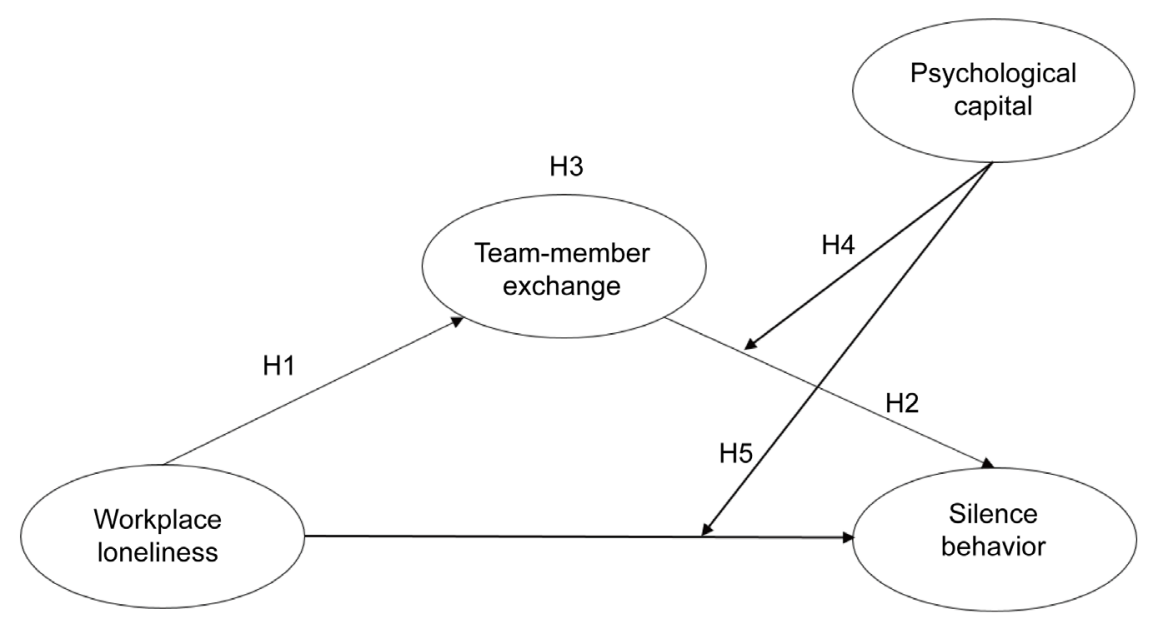

Figure 1. Proposed theoretical model. 


\subsection{Implications for Workplace Loneliness and Team-Member Exchange}

We think that workplace loneliness negatively affects team member exchanges. Wright (2005) on the workplace loneliness more clear definition is given, he thinks the workplace loneliness is due to the individual in the workplace expected gain of interpersonal relationship and reality interpersonal differences in quantity or quality, and individual lacks the ability to compensate for the difference in a lonely experience, this kind of lonely experience will make employees lack of identity for organization members, make their emotional needs are in the organization, and caused a series of negative consequences (Wright, 2005; Erdil \& Ertosun, 2011). Workplace loneliness includes two dimensions, namely emotional deprivation and loss of organizational membership. Emotional deprivation refers to the fact that employees' attachment needs are not satisfied because their interpersonal relationship in the organization is defective in quantity or quality, which will lead to their emotional indifference and numbness. Lack of sense of membership refers to employees' lack of sense of belonging and identity to the organization, which will lead to employees' disconnection from the network of organizational relations and a sense of alienation from other members of the organization (Wright, 2005; Wright et al., 2006; Lam \& Lau, 2012; Chen et al., 2016). When employees experience such loneliness in the workplace, employees will perceive poor interpersonal exchange with team members, as well as team members' alienation from them. According to social exchange theory, employees don't perceive this emotional exchange, which leads to the lack of loyalty and commitment to the team so that employees will not take the initiative to exchange with other colleagues in the team, or even actively avoid the exchange with team members, resulting in lower quality team members exchange. Therefore, we propose the following hypothesis:

H1: Workplace loneliness has a significant negative impact on team-member exchange.

\subsection{The Mediating Role of Team-Member Exchange}

We think that team-member exchange has a negative impact on employees' silence behavior. Seers (1989) defines team-member exchange as the individual member's perception of the overall exchange relationship between the individual member and other members of the team and describes the quality and reciprocal interaction of the working relationship between the individual member and his/her colleagues in the team (Seers, 1989; Schermuly \& Meyer, 2016). In subsequent studies, it was further defined as a reciprocal relationship between members and the team in terms of point of view transmission and feedback, assistance to others, as well as corresponding point of view acceptance and assistance from others (Seers, 1989; Seers, Petty, \& Cashman, 1995). The quality is used to measure the exchange of ideas, communication, assistance and support among team members, and it is pointed out that it is based on individual abilities and interests and 
needs of other members. Meanwhile, it is emphasized that the reciprocity of the relationship means that an individual who is treated positively by other members has the obligation to treat others in the same positive way (Banks, Batchelor, Seers, O'Boyle Jr., Pollack, \& Gower, 2014). However, the quality of team-member exchange varies with the content and process of the exchange between individual members (Liao, Liu, \& Loi, 2010). For example, the low quality is based on the need to complete the task, and the team members with low quality have less return from the team due to the lack of cooperation, communication and trust. And high quality in addition to the need to perform the job, there are social emotion exchange, such as members of the mutual respect and trust each other, treat colleagues as friends, etc., as individual members have a high quality team members exchange, heralding the individuals are more willing to pay for the team effort, and the corresponding social return, from the team members work to assist each other, is beneficial to strengthen the team members agreed that, at the same time also let members aware of the importance of the team (Sherony \& Green, 2002). Therefore, we believe that high-quality team member exchange will make employees willing to make positive efforts for the development of the team, take the initiative to find and change problems in the team, and exchange rewards for the team through their positive performance. However, the low-quality team member exchange will make employees avoid social opportunities. Due to the lack of confidence and support of team members, they will keep silence about problems or work Suggestions in the team and do not expect the team to reward themselves for their efforts, thus resulting in silence behavior. These are consistent with the principle of reciprocity mentioned in social exchange theory (Gouldner, 1960). In conclusion, based on hypothesis 1 , we propose the following hypothesis:

$\mathrm{H} 2$ : Team-member exchange has a significant negative effect on silence behavior.

H3: Team-member exchange mediates the relationship between workplace loneliness and silence behavior.

\subsection{The Moderating Role of Psychological Capital}

We think that psychological capital can alleviate some of the negative consequences of workplace loneliness and low-quality team-member exchange. Luthans, Luthans and Luthans (2004) pointed out that positive psychological capital refers to the four positive psychological abilities of confidence or self-efficacy, hope, confidence and resilience, which are all psychological states that can be measured, developed and managed, and enable individuals to achieve more effective work performance. Self-confidence (or self-efficacy) refers to the degree of trust an individual has in his/her ability to exert motivation, cognitive resources and action steps to successfully manage a particular task in a given situation (Stajkovic \& Luthans, 1998); Hope refers to a positive motivational state of achievement based on the interaction between agents (goal-directed vitality) and paths (plans to achieve goals) (Snyder, Irving, \& Anderson, 1991); Optimism can be defined by the two key dimensions (persistence and universal depth) of people's 
explanatory styles for good events and bad events. It refers to the positive explanatory style in which people attribute good events to internal, lasting and universal causes and bad events to external, temporary and specific causes (Seligman, 2002). Resilience is the ability to recover quickly from adversity. Resilience is demonstrated by a firm acceptance of reality, a belief in the meaning of life supported by stable values, and an uncanny ability to cope temporarily and adapt to major changes (Coutu, 2002; Luthans, Vogelgesang, \& Lester, 2006). In conclusion, psychological capital, as a positive psychological resource of individuals, can be used to supplement the shortage of resources for work (Raja, Azeem, Haq, \& Naseer, 2020). When employees' psychological capital high, can make up for staff in the workplace loneliness lonely experience, walked out of the loneliness in the workplace and more easily bring the experience of bad due to external causes, which can actively looking for a way to solve the present situation, and believe in yourself can be settled as soon as possible, quickly recover from the dilemma and adjustment to work best, to offset part of the negative consequences of loneliness. Similarly, when the employee's psychological capital is high, it will make up for the lack of resources brought by the low-quality team member exchange, or supplement the resources of emotional exchange, and the employee will regain hope and confidence, and believe that he can improve the quality of team member exchange, thus reducing the negative impact of team member exchange. Therefore, we make the following assumptions:

H4: Psychological capital negatively moderates the direct effect of workplace loneliness on silence behavior, that is, the higher the psychological capital, the weaker the direct effect.

H5: Psychological capital negatively moderates the indirect effect of workplace loneliness on silence behavior through team-member exchange, that is, when psychological capital is higher, the indirect effect is weaker.

\section{Methods}

\subsection{Participants and Procedure}

This survey mainly collects data online through questionnaires, and the respondents are all employees of enterprises in south China. Before starting the research, we will contact with employees in the enterprise in advance to briefly inform them of the research purpose and process. In order to obtain reasonable and effective data, this study adopted a three-stage, multi-source paired sample survey. In this study, data of four variables of the research model were investigated in three times. Data of workplace loneliness was obtained in Time 1; data of team member exchange was obtained in Time 2; data of employee silence behavior and psychological capital were obtained in Time 3. The three surveys were conducted three months apart to prevent the effect of time effect and ensure the validity of the data. In the screening of invalid questionnaires, the first criterion is the completeness of completion. If three options are not answered, it will be judged as invalid. Secondly, if there are 10 consecutive items answered with the 
same choice, it is also judged to be invalid.

After eliminating the invalid questionnaires, the data of 295 employees were finally obtained. Among them, 47.8 percent were males and 52.5 percent were females. Those aged 25 or below accounted for 23.4 percent, those aged $26-30$ accounted for 30.1 percent, those aged 31 - 35 accounted for 27.2 percent, those aged 36 - 40 accounted for 8.7 percent, those aged 41 - 45 accounted for 4.8 percent, and those aged 46 or above accounted for 5.8 percent. And, college and bachelor's degrees accounted for the largest proportion (25.6\% and 52.0\%, respectively), high school and technical secondary school education below 5.8 percent, and master's degree or above 17.6 percent. In addition, two-four years' working experience were the most, accounting for $29.8 \%$, those who had worked for more than 10 years accounted for $21.2 \%$, those who have worked for less than two years account for $19.2 \%$, those who had worked five to seven years accounted for $15.4 \%$, while those who had worked eight to ten years accounted for $14.4 \%$. Moreover, the number of subordinates at the grass-roots level was the largest, accounting for $60.6 \%$ of the total, grass-roots managers, accounting for 25.3 percent of the total, middle managers accounted for $13.1 \%$ of the total, top management accounts for $1.0 \%$ of the total. In general, the sample distribution is relatively average.

\subsection{Measures}

Workplace loneliness. Based on the scale of workplace loneliness compiled by Wright et al. (2006), Chinese scholars Peng et al. (2017) and Chen et al. (2016) translated the Chinese version of the questionnaire by program and conducted the research in China, and the internal consistency coefficient is also ideal, respectively $0.87,0.88$. Thus, we adopted the Chinese version of the questionnaire for research, including 16 questions in this study. Likert scale 5 was used, ranging from 1 (strongly disagree) to 5 (strongly agree).

Team-member exchange. In this study, we cited Seers (1989)'s scale developed by, with a total of 10 items. The reliability and validity of the scale have been well verified. Likert scale 5 was used, ranging from 1 (strongly disagree) to 5 (strongly agree).

Silence behavior. In this study, we used the employee silence scale in the Tangirala and Ramanujam (2008) study, with a total of 5 questions. It has been used by Chinese scholars and proved to have good reliability and validity (Li, Ling, \& Liu, 2012). Likert scale 5 was used, ranging from 1 (strongly disagree) to 5 (strongly agree).

Psychological capital. In this study, we used the Chinese version of psychological capital scale (pcq-24) compiled by Luthans et al. (2007) and revised by professor Li. The scale consists of four dimensions of self-efficacy, hope, optimism and resilience of psychological capital. Each dimension is measured by six items, with a total of 24 items. Likert scale 5 was used, ranging from 1 (strongly disagree) to 5 (strongly agree). 


\section{Results}

\subsection{Descriptive Statistics and Correlations}

In this study, SPSS 23.0 software was used to conduct correlation analysis on the main variables and related control variables involved in the study. Pearson correlation coefficient method was used to test the correlation among the variables in this study. The specific analysis results are shown in Table 1 . There is a significant negative correlation between workplace loneliness and team-member exchange $(r=-0.22, p<0.01)$. There is a significant negative correlation between team-member exchange and silence behavior $(r=-0.35, p<0.01)$. There is a significant positive correlation between workplace loneliness and silence behavior $(r=0.27, p<0.01)$. There is a significant negative correlation between psychological capital and silence behavior $(r=-0.38, p<0.01)$. These results lay the foundation for the next causal analysis.

\subsection{Hypothesis Testing}

We used Mplus 7.4 for hypothesis testing, using the method of SEM, and the results of hypothesis testing are shown in Figure 2.

Table 1. Descriptive statistics and correlations.

\begin{tabular}{ccccccc}
\hline & $\mathrm{M}$ & $\mathrm{SD}$ & 1 & 2 & 3 & 4 \\
\hline 1) workplace loneliness & 4.294 & 0.375 & $\mathbf{( 0 . 8 9 )}$ & & & \\
2) team-member exchange & 4.052 & 0.486 & $-0.22^{* *}$ & $\mathbf{( 0 . 8 5 )}$ & & \\
3) silence behavior & 4.202 & 0.513 & $0.27^{* *}$ & $-0.35^{* *}$ & $\mathbf{( 0 . 9 2 )}$ & \\
4) psychological capital & 4.050 & 0.755 & $-0.35^{* *}$ & $0.36^{* *}$ & $-0.38^{* *}$ & $(0.91)$
\end{tabular}

Note: $N=295$. Cronbach's alpha is displayed in parentheses. ${ }^{* *} p<0.001 ;{ }^{* *} p<0.01 ;{ }^{*} p<0.05$.

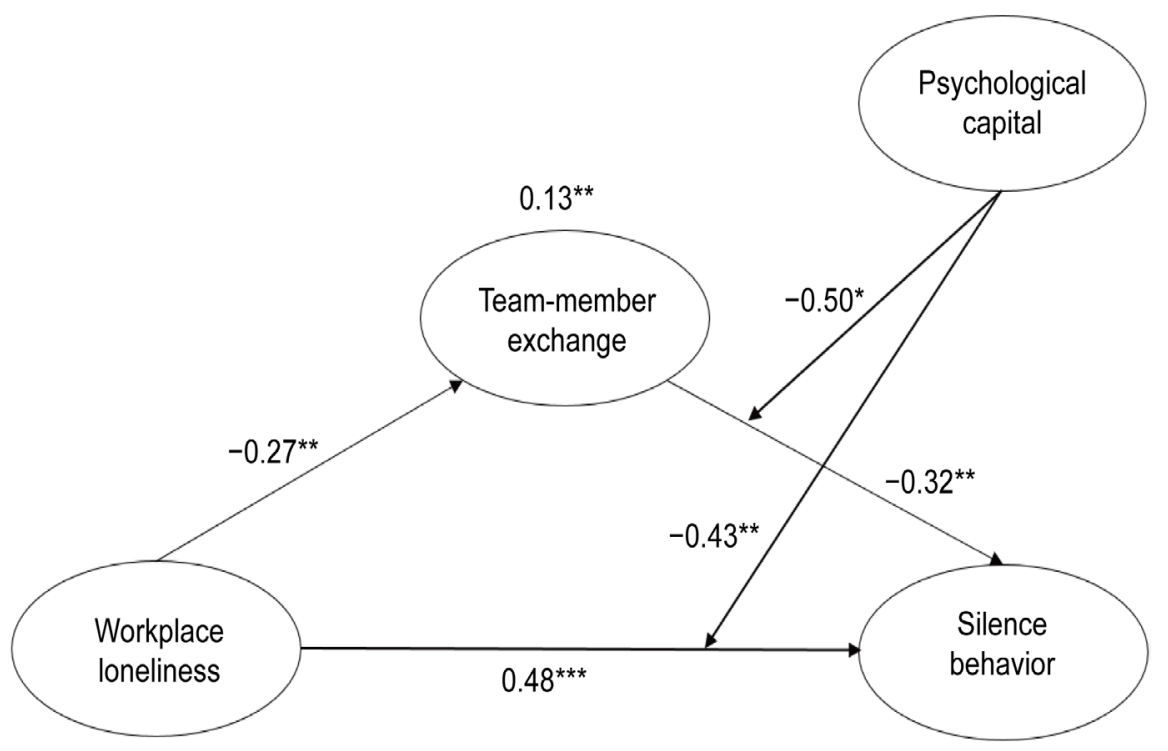

Figure 2. Structural equation modeling results. 
We can see that workplace loneliness had a significant negative effect on team-member exchange $(\beta=-0.27, p<0.01)$, Hypothesis 1 thus was supported. team-member exchange had a significant negative on silence behavior $(\beta=-0.32$, $p<0.01)$, Hypothesis 2 thus was supported. The indirect effect of workplace loneliness on workplace loneliness through team-member exchange was significant $(\beta=-0.13, p<0.01)$. And to test the robustness of the mediation effect, we also employed bootstrapping produces, resampling 5000 times and creating $95 \%$ confidence intervals (Results are shown in Table 2). The indirect effect of workplace loneliness on workplace loneliness through team-member exchange was significant $(\beta=-0.37, p<0.05, \mathrm{CI}=[0.13,0.29])$, Hypothesis 3 thus was supported.

Moreover, psychological capital moderated the direct effect of workplace loneliness on silence behavior $(\beta=-0.50, p<0.05)$, Hypothesis 4thus was supported. Psychological capital moderated the indirect effect of workplace loneliness on silence behavior through team-member exchange $(\beta=-0.32, p<0.01)$, Hypothesis 5 thus was supported. To test the robustness of the mediation effect, we also employed bootstrapping produces, resampling 5,000 times and creating 95\% confidence intervals (Results are shown in Table 3 ). Hypothesis 4 and Hypothesis 5 were further supported.

In order to demonstrate the moderating effect of psychological capital more intuitively, we draw the moderating effect diagram, as shown in Figure 3 and Figure 4.

From the above results, it can be seen that the test results of correlation analysis between variables lay a foundation for hypothesis testing. And further causal analysis between variables and tests of mediating and moderating effects supported Hypotheses 1-5.

Table 2. Bootstrap test result of mediating effect.

\begin{tabular}{cccc}
\hline Path & Effect & $2.5 \%$ LLCL & 97.5\% LLCL \\
\hline Indirect effect & $0.37^{*}$ & 0.13 & 0.29 \\
Direct effect & $0.12^{*}$ & 0.04 & 0.22 \\
Full & $0.49^{*}$ & 0.09 & 0.31 \\
\hline
\end{tabular}

Note: $N=295 .{ }^{* * *} p<0.001 ;{ }^{* *} p<0.01 ;{ }^{*} p<0.05$.

Table 3. Bootstrap test result of moderating effect.

\begin{tabular}{|c|c|c|c|c|}
\hline & Group & Effect & $2.5 \% \mathrm{LLCL}$ & 97.5\% LLCL \\
\hline \multirow{3}{*}{ Direct effect } & HighPsychological capital $(\mathrm{M}+1 \mathrm{SD})$ & -0.52 & -0.02 & 0.12 \\
\hline & LowPsychological capital (M - 1SD) & $-0.14^{*}$ & -0.05 & -0.04 \\
\hline & Difference & $0.48^{*}$ & 0.01 & 0.11 \\
\hline \multirow{3}{*}{ Indirect effect } & HighPsychological capital $(\mathrm{M}+1 \mathrm{SD})$ & -0.62 & -0.03 & 0.18 \\
\hline & LowPsychological capital (M - 1SD) & $-0.15^{*}$ & -0.23 & -0.07 \\
\hline & Difference & $0.77^{*}$ & 0.02 & 0.18 \\
\hline
\end{tabular}

Note: $N=295 .{ }^{* * *} p<0.001 ;{ }^{* *} p<0.01 ;{ }^{*} p<0.05$. 


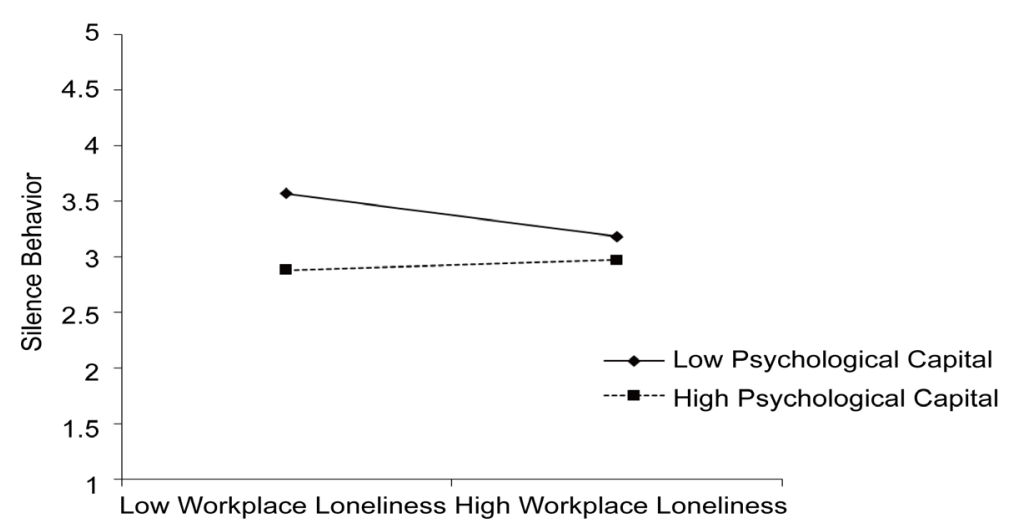

Figure 3. Interaction between workplace loneliness and psychological capital on silence behavior.

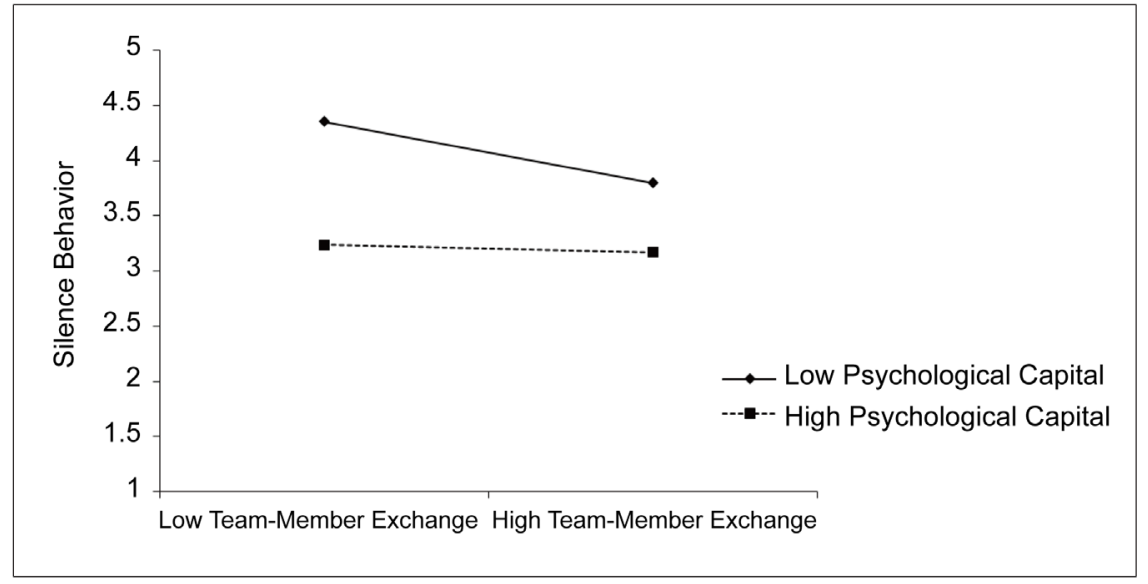

Figure 4. Interaction between team-member exchange and psychological capital on silence behavior.

\section{Conclusion}

\subsection{Theoretical Implications}

First, through the existing literature review, it can be found that there are few studies on workplace loneliness in the context of Chinese culture, which means that there is not enough attention. As a major force of domestic economic development, the mental health of workplace employees should be paid attention to. Starting from the dark side of workplace loneliness, this study involves a new research field and new focus to explore the negative effects of workplace loneliness, and hopes to attract academic attention and find more ways to alleviate its negative effects. Second, most previous studies on workplace loneliness have focused on the relationship between two variables, and the mediating mechanism has not been further discussed. This study, by introducing the mediating variable of team-member exchange, reveals the internal influencing mechanism of workplace loneliness and deepens the research on the formation mechanism of workplace loneliness. 


\subsection{Practical Implications}

First of all, employees should pay attention to the harm brought by workplace loneliness. On the one hand, employees should strengthen their awareness of workplace loneliness, actively carry out interpersonal communication in the organization, and effectively prevent workplace loneliness. On the other hand, if you are troubled by loneliness in the workplace, you should face it with a positive and optimistic attitude. While adjusting yourself, you can seek help from your family and friends and communicate with them more often. Secondly, the organization should strengthen the communication and interaction among employees, and provide more opportunities for employees to cooperate and help each other, so that employees can feel the trust between colleagues, so as to prevent workplace loneliness. At the same time, this can also let employees feel the good atmosphere of the organization, willing to stay in the organization. Finally, organizations should pay attention to employees' mental health. The mental health status of employees directly affects their performance level. A set of mental health security system has been established to enable employees to get rid of psychological problems and better participate in work.

\subsection{Limitations and Future Research}

First of all, the research samples in this study are mainly from enterprises in southern China, so the sample extraction is not comprehensive enough, and the applicability of the research results in other regions of China remains to be tested. Future studies should enrich the source areas of samples and extract samples comprehensively, so as to improve the external validity of the research conclusions. Then, in terms of the selection of subjects, due to the time limit, the sample size collected is limited, so the complete random selection cannot be achieved. Future studies can further expand the number of subjects. In addition, the research method of this study is in the form of questionnaire, and there may be a social approval effect in the responses of subjects, which may have a certain influence on the research results. Future studies can use tracking data analysis to improve the study design. Finally, future research should try to explore more possible mediating variables and regulating variables, and explain their mechanism of action from a new theoretical perspective.

\section{Conflicts of Interest}

The author declares no conflicts of interest regarding the publication of this paper.

\section{References}

Banks, G. C., Batchelor, J. H., Seers, A., O’Boyle Jr., E. H., Pollack, J. M., \& Gower, K. (2014). What Does Team-Member Exchange Bring to the Party? A Meta-Analytic Review of Team and Leader Social Exchange. Journal of Organizational Behavior, 35, 273-295. https://doi.org/10.1002/job.1885

Blau, P. M. (1964). Social Exchange Theory (p. 62). 
Chen, Y., Wen, Z., Peng, J., \& Liu, X. (2016). Leader-Follower Congruence in Loneliness, LMX and Turnover Intention. Journal of Managerial Psychology, 31, 864-879. https://doi.org/10.1108/JMP-06-2015-0205

Cook, K. S., Cheshire, C., Rice, E. R., \& Nakagawa, S. (2013). Social Exchange Theory. In Handbook of Social Psychology (pp. 61-88). Dordrecht: Springer. https://doi.org/10.1007/978-94-007-6772-0_3

Coutu, D. L. (2002). How Resilience Works. Harvard Business Review, 80, 46-56.

Dussault, M., \& Thibodeau, S. (1997). Professional Isolation and Performance at Work of School Principals. Journal of School Leadership, 7, 521-536. https://doi.org/10.1177/105268469700700505

Erdil, O., \& Ertosun, Ö. G. (2011). The Relationship between Social Climate and Loneliness in the Workplace and Effects on Employee Well-Being. Procedia-Social and Behavioral Sciences, 24, 505-525. https://doi.org/10.1016/j.sbspro.2011.09.091

Gouldner, A. W. (1960). The Norm of Reciprocity: A Preliminary Statement. American Sociological Review, 25, 161-178. https://doi.org/10.2307/2092623

Homans, G. C. (1958). Social Behavior as Exchange. American Journal of Sociology, 63, 597-606. https://doi.org/10.1086/222355

Lam, L. W., \& Lau, D. C. (2012). Feeling Lonely at Work: Investigating the Consequences of Unsatisfactory Workplace Relationships. The International Journal of Human Resource Management, 23, 4265-4282. https://doi.org/10.1080/09585192.2012.665070

Lawler, E. J., \& Thye, S. R. (1999). Bringing Emotions into Social Exchange Theory. Annual Review of Sociology, 25, 217-244. https://doi.org/10.1146/annurev.soc.25.1.217

Li, R., Ling, W. Q., \& Liu, S. S. (2012). The Antecedents and Outcomes of Psychological Ownership for the Organization: An Analysis from the Perspective of Person-Situation Interactions. Acta Psychologica Sinica, 44, 1202-1216.

https://doi.org/10.3724/SP.J.1041.2012.01202

Liao, H., Liu, D., \& Loi, R. (2010). Looking at Both Sides of the Social Exchange Coin: A Social Cognitive Perspective on the Joint Effects of Relationship Quality and Differentiation on Creativity. Academy of Management Journal, 53, 1090-1109. https://doi.org/10.5465/amj.2010.54533207

Luthans, F., Avolio, B. J., Avey, J. B., \& Norman, S. M. (2007). Positive Psychological Capital: Measurement and Relationship with Performance and Satisfaction. Personnel Psychology, 60, 541-572. https://doi.org/10.1111/j.1744-6570.2007.00083.x

Luthans, F., Luthans, K. W., \& Luthans, B. C. (2004). Positive Psychological Capital: Beyond Human and Social Capital. https://doi.org/10.1016/j.bushor.2003.11.007

Luthans, F., Vogelgesang, G. R., \& Lester, P. B. (2006). Developing the Psychological Capital of Resiliency. Human Resource Development Review, 5, 25-44. https://doi.org/10.1177/1534484305285335

Ozcelik, H., \& Barsade, S. G. (2018). No Employee an Island: Workplace Loneliness and Job Performance. Academy of Management Journal, 61, 2343-2366. https://doi.org/10.5465/amj.2015.1066

Peng, J., Chen, Y., Xia, Y., \& Ran, Y. (2017). Workplace Loneliness, Leader-Member Exchange and Creativity: The Cross-Level Moderating Role of Leader Compassion. Personality and Individual Differences, 104, 510-515. https://doi.org/10.1016/j.paid.2016.09.020

Raja, U., Azeem, M. U., Haq, I. U., \& Naseer, S. (2020). Perceived Threat of Terrorism and Employee Outcomes: The Moderating Role of Negative Affectivity and Psychological Capital. Journal of Business Research, 110, 316-326. 
https://doi.org/10.1016/j.jbusres.2020.01.026

Reinking, K., \& Bell, R. A. (1991). Relationships among Loneliness, Communication Competence, and Career Success in a State Bureaucracy: A Field Study of the "Lonely at the Top" Maxim. Communication Quarterly, 39, 358-373. https://doi.org/10.1080/01463379109369812

Rhoades, L., \& Eisenberger, R. (2002). Perceived Organizational Support: A Review of the Literature. Journal of Applied Psychology, 87, 698. https://doi.org/10.1037/0021-9010.87.4.698

Schermuly, C. C., \& Meyer, B. (2016). Good Relationships at Work: The Effects of Leader-Member Exchange and Team-Member Exchange on Psychological Empowerment, Emotional Exhaustion, and Depression. Journal of Organizational Behavior, 37, 673-691. https://doi.org/10.1002/job.2060

Seers, A. (1989). Team-Member Exchange Quality: A New Construct for Role-Making Research. Organizational Behavior and Human Decision Processes, 43, 118-135. https://doi.org/10.1016/0749-5978(89)90060-5

Seers, A., Petty, M. M., \& Cashman, J. F. (1995). Team-Member Exchange under Team and Traditional Management: A Naturally Occurring Quasi-Experiment. Group \& Organization Management, 20, 18-38. https://doi.org/10.1177/1059601195201003

Seligman, M. E. P. (2002). Authentic Happiness. New York: Free Press.

Sherony, K. M., \& Green, S. G. (2002). Coworker Exchange: Relationships between Coworkers, Leader-Member Exchange, and Work Attitudes. Journal of Applied Psychology, 87, 542. https://doi.org/10.1037/0021-9010.87.3.542

Snyder, C. R., Irving, L., \& Anderson, J. (1991). Hope and Health: Measuring the Will and the Ways. In Handbook of Social and Clinical Psychology (pp. 285-305). Berlin: Springer.

Stajkovic, A. D., \& Luthans, F. (1998). Social Cognitive Theory and Self-Efficacy: Going beyond Traditional Motivational and Behavioral Approaches. Organizational Dynamics, 26, 62-75. https://doi.org/10.1016/S0090-2616(98)90006-7

Tangirala, S., \& Ramanujam, R. (2008). Employee Silence on Critical Work issues: The Cross-Level Effects of Procedural Justice Climate. Personnel Psychology, 61, 37-68. https://doi.org/10.1111/j.1744-6570.2008.00105.x

Wright, S. L. (2005). Loneliness in the Workplace.

Wright, S. L., Burt, C. D. B., \& Strongman, K. T. (2006). Loneliness in the Workplace: Construct Definition and Scale Development. New Zealand Journal of Psychology, 35, 59-68. 